\title{
A quantitative approach to the determination of drug release from reverse-phase evaporation lipid vesicles. The influence of sodium ion-pair formation on warfarin partitioning and permeability
}

\author{
Ardouin A. Cools and Lambert H.M. Janssen \\ Department of Pharmaceutical Chemistry. Subfaculty of Pharmacy. State University of Utrecht. \\ 3511 GH Utrecht (The Netherlands)
}

(Received January 23rd, 1984)

(Modified version received March 20th, 1984)

(Accepted March 29th, 1984)

\section{Summary}

The influence of sodium ion-pair formation on warfarin partitioning and permeability has been investigated using reverse-phase evaporation lipid vesicles. An experimental method for the isolation of the vesicles having known amounts of encapsulated drug has been described. The partitioning of warfarin between phospholipid membrane and aqueous phase at different $\mathrm{Na}^{+}$concentrations was determined in separate experiments. Thus, using a two-compartment cylinder assembly the influence of $\mathrm{Na}^{+}$concentration on the release rate of the encapsulated warfarin from the vesicles could be measured quantitatively. It appears that under the present experimental conditions warfarin partitioning does depend on $\mathrm{Na}^{+}$concentration whereas vesicle permeability towards warfarin does not seem to be affected.

\section{Introduction}

Several investigators have studied the efflux of drugs from phospholipid vesicles. Multilamellar (Ahmed et al., 1980; Arrowsmith et al., 1983) and unilamellar (Hermetter and Paltauf, 1981; Muranushi et al.. 1980; Juliano and Stamp, 1979) systems have been examined from two main points of interest. First, phospholipid

Correspondence: L.H.M. Janssen, Dept. of Pharmaceutical Chemistry. Subfaculty of Pharmacy, State University of Utrecht, Catharijnesingel $60,3511 \mathrm{GH}$ Utrecht, The Netherlands. 
bilayers may simulate some fundamental properties of biological membranes and constitute a model system to investigate passive drug transport. Second, there is the possible application of phospholipid vesicles as a drug delivery system. Both objectives have been faced with the serious problem that until recently no method for the preparation of a homogeneous and well-characterized population of unilamellar vesicles with a sufficiently large internal volume was available. Yet, knowledge of these properties is necessary for the purpose of a quantitative approach of transport phenomena if water-soluble compounds are to be encapsulated and released. Fortunately a method for the prenaration of phospholipid vesicles that would meet those requirements was described by Szoka and Papahadjopoulos (1978). We used this method in our present investigation where we studied the influence of ion-pair formation on the efflux rate of the anticoagulant warfarin from phospholipid vesicles.

In a previous communication from our laboratory (van der Giesen and Janssen, 1982 ) it was reported that the apparent partition coefficient of warfarin at $\mathrm{pH} 10.0$ (warfarin has a pK of 5.0 and is completely dissociated under those conditions) was increased by the presence of $\mathrm{Na}^{+}$ions. A linear relationship between the logarithm of the apparent partition coefficient $K_{\text {app }}$ and the negative logarithm of the sodium ion concentration $\mathrm{pNa}$ was observed. This result could be explained by assuming the formation of ion-pairs between the anion of warfarin and $\mathrm{Na}^{+}$. In a follow-up study we found a linear relationship between the logarithm of the rate constant for the diffusion of warfarin through octanol-impregnated Millipore filters and $\mathrm{pNa}$ (Cools and Janssen, 1983).

It seemed appropriate to extend the investigations on the influence of ion-pair formation on transport kinetics to the area of phospholipid bilayer passage, to find out if comparable results could be obtained in a more realistic but at the same time more complicated model system.

\section{Materials and Methods}

\section{Chemicals}

Warfarin was purchased from ACF Chemiefarma (ACF. Maarssen. The Netherlands) and used as supplied. Dipalmitoylphosphatidylcholine (DPPC) was purchased from Fluka. Sephadex G25 coarse from Pharmacia and Triton X-100 from Sigma Chemicals. All experiments were performed at $\mathrm{pH} 11.5(10 \mathrm{mM} \mathrm{NaOH})$.

Measurement of the partitioning of warfarin between phospholipid membrane and aqueous phase at different $\mathrm{Na}{ }^{+}$concentrations

DPPC (40 mg) was dissolved in $5 \mathrm{ml}$ chloroform in a round-bottomed flask and dried in vacuo in a rotary evaporator. The remaining phospholipid film was suspended in $5.5 \mathrm{ml}$ solution. containing warfarin $(0.05 \mathrm{mM}), \mathrm{NaOH}(10 \mathrm{mM})$ and $\mathrm{NaCl}(0 \mathrm{mM}, 40 \mathrm{mM}, 100 \mathrm{mM}, 500 \mathrm{mM}, 1000 \mathrm{mM})$. The multilamellar liposomes formed in this way, essentially as described by Bangham et al. (1965), were stored at $45^{\circ} \mathrm{C}$ for $1 \mathrm{~h}$ and thereafter at $30^{\circ} \mathrm{C}$ for the next $20 \mathrm{~h}$ before use. Liposomes $(5 \mathrm{ml})$ 
were then transferred to a polypropylene centrifuge tube. 6 centrifuge tubes. containing liposomes formed at different $\mathrm{Na}^{+}$concentrations, were centrifuged in an ultracentrifuge (MSE superspeed 75) at $100.000 \mathrm{~g}$ for one night at $30^{\circ} \mathrm{C}$. The next day the warfarin concentrations of the supernatants were measured. It was determined that no warfarin was adsorbed to the walls of the centrifuge subes.

For the purpose of the determination of the apparent partition coefficicnts $(K$, , the membranous volume of the liposomes in the gel state was calculated. takins into account a value of $45 \AA^{2}$ for the cross-sectional area of one DPPC molecule and a value of $42 \AA$ for the thickness of a bilayer. The values are taken from Chapman et al. (1967) and from Levine et al. (1973). $1 \mathrm{mg}$ DPPC then corresponds to a membranous volume of $0.776 \mu \mathrm{l}$.

Preparaion of reverse-phase evaporation lipid cesicles

Reverse-phase evaporation lipid vesicles (REVs) were prepared at different Na concentrations according to the method of Szoka and Papahadjopoulos (1978). 20 $\mathrm{mg}$ DPPC was dissolved in $5 \mathrm{ml}$ ether and $5 \mathrm{ml}$ chloroform in a round-boltomed flask. $1.5 \mathrm{ml}$ Solution containing warfa $\mathrm{n}(6 \mathrm{mM})$. $\mathrm{NaOH}(10 \mathrm{mM})$ and $\mathrm{NaCl}(0$ $\mathrm{mM}, 30 \mathrm{mM}, 100 \mathrm{mM}, 600 \mathrm{mM}, 1000, \mathrm{MM}$ ) was added next and the mixture treated ultrasonically at $50^{\circ} \mathrm{C}$ in an ultrasonic bath for $3 \mathrm{~min}$. At the end of that time a milky single-phase dispersion was left. Then the ether and chloroform were carefully evaporated at reduced pressure at $45^{\circ} \mathrm{C}$ from the round-bottomed flask which was fitted to a rotary evaporator by means of a long extension glass tube. The conditions were such that the volume of a REV preparation after complete evaporation of the organic liquids amounted to about $1.1 \mathrm{ml}$. The REVs were stored at $45^{\circ} \mathrm{C}$ for one hour and at $30^{\circ} \mathrm{C}$ for the next $20 \mathrm{~h}$ before use.

The final volume of a preparation will hereafter be called $\mathrm{V}$. Warfarin. $\mathrm{NaCl}$ and DPPC then will be concentrated by a factor $1.5 \mathrm{~V}^{-1}$. Two portions of $0.5 \mathrm{ml}$ of each preparation were used separately as described below. At this point it should be noted that each portion will contain $20 \times 0.5 \times \mathrm{V}{ }^{\prime} \mathrm{mg}$ DPPC corresponding with a membranous volume $V_{M}$ :

$\mathrm{V}_{\mathrm{M}}=20 \times 0.5 \times \mathrm{V}^{-1} \times 0.776 \times 10^{-3}(\mathrm{ml})$

Subtracting $\mathrm{V}_{\mathrm{M}}$ from the total volune of a portion $(0.5 \mathrm{ml})$ then vields the volume of the aqueous phase $V_{A}$ :

$V_{\mathrm{A}}=0.5-\mathrm{V}_{\mathrm{M}}(\mathrm{ml})$

The total amount of warfarin, $m_{1,1}(\mu \mathrm{mol})$, in each portion may he derived from the original wartarin concentration. The concentration of warfarin in the ayuests phase. $[W]_{\text {A }}$. may be expressed either as the quotient of the amount of warfarin in the aqueous phase and the volume of the aqueous phase. or as the concentration of warfarin in the membranous phase divided by $K_{\text {app }}$ (Eyns. 3 and 4):

$[\mathrm{W}]_{\mathrm{A}}=\frac{\mathrm{m}_{1 \mathrm{u}}-\mathrm{m}_{\mathrm{M}}}{0.5-\mathrm{V}_{\mathrm{M}}}(\mathrm{mM})$ 
$[\mathrm{W}]_{\mathrm{A}}=\frac{\mathrm{m}_{\mathrm{M}}}{\mathrm{K}_{\mathrm{app}} \cdot \mathrm{V}_{\mathrm{M}}}(\mathrm{mM})$

Equating the last parts of expressions 3 and 4 yields the value for the amount of warfarin in the membranous phase:

$\mathrm{m}_{\mathrm{M}}=\frac{\mathrm{K}_{\mathrm{upp}} \cdot \mathrm{V}_{\mathrm{M}} \cdot \mathrm{m}_{\mathrm{tot}}}{\mathrm{K}_{\mathrm{app}}-\mathrm{V}_{\mathrm{M}}+0.5-\mathrm{V}_{\mathrm{M}}}(\mu \mathrm{mol})$

It then follows that the amount of warfarin in the aqueous phase is:

$\mathrm{m}_{\mathrm{A}}=\mathrm{m}_{1+\mathrm{t}}-\mathrm{m}_{\mathrm{M}}(\mu \mathrm{mol})$

\section{Isolation of REV's using gel filtration}

To remove the warfarin not captured by the vesicles $0.5 \mathrm{ml}$ REVs were put on top of a Sephadex column (G25 Coarse, $10 \mathrm{ml}$ bed volume, diameter $10 \mathrm{~mm}$ ) and eluted with the same solution as used for the preparation of the vesicles except that warfarin was absent (elution rate $0.9 \mathrm{ml} / \mathrm{min}$ ). This solution also was used to swell the Sephadex before use. The elution procedure was performed twice in exactly the same way for each vesicle preparation. The first time it was used to characterize the elution pattern at that specific $\mathrm{Na}^{+}$concentration and to determine the amount of warfarin encapsulated in the REVs $\left(\mathrm{m}_{\mathrm{REV}}\right)$. Therefore subsequent fractions of $0.6 \mathrm{ml}$ were collected and diluted with water to $12.8 \mathrm{ml}$. The samples were treated with Triton X-100 (1\%) at $60^{\circ} \mathrm{C}$ for $2 \mathrm{~h}$ to lyze the vesicles. Then warfarin was measured at $308 \mathrm{~nm}$.

The elution patterns showed two peaks: a first narrow peak of warfarin that had been captured by the REVs and a second broad one containing bulk warfarin. The amount of warfarin encapsulated in the REVs, $m_{R E V}(\mu \mathrm{mol})$, was derived from the sum of the absorbances of the first peak using 13.6 as the molar extinction coefficient of warfarin. The amount of warfarin in the internal water phase $\left(m_{1}\right)$ then could be found by subtracting the amount of warfarin in the membranous phase from $\mathrm{m}_{\mathrm{RI}: \mathrm{V}}$ :

$\mathrm{m}_{\mathrm{I}}=\mathrm{m}_{\mathrm{HI} \cdot \mathrm{V}}-\mathrm{m}_{\mathrm{M}}(\mu \mathrm{mol})$

The volume of the internal aqueous phase then was given by:

$V_{1}=\frac{m}{[W]_{A}}(\mu 1)$

The result of the elution patterns was used to predict the warfarin content of a specific amount of REVs $(2.0 \mathrm{ml}$, i.e. 3.4 fractions $)$ which in an analogously performed second elution, were collected at once for the purpose of an efflux experiment. The quotient of the warfarin content of that specific amount of REVs 
and the warfarin content of all the REVs eluted in the first elution was used to find the values of $m_{1}, m_{M}, V_{1}$ and $V_{M}$ for that specific amount of REVs.

A single isolation procedure could be performed within $8 \mathrm{~min}$.

Meusurement of diffusion of warfarin out of REVS

For this purpose a slightly modified cylinder assembly was used as described before (Cools and Janssen, 1983). The volume of the two compartinents this time was $2.3 \mathrm{ml}$ and $17.0 \mathrm{ml}$, respectively. Into the smaller barrel $2 \mathrm{ml}$ isolated REVs were pipetted. A Millipore filter (type VC, pore size $0.1 \mu \mathrm{m}$ ) was applied to the top of this barrel. The pore size was small enough to prevent permeation of vesicles through the filter, whereas warfarin could pass through it easily (see below). This membrane therefore functions as a separating or dialysis membrane. In the iext this membrane will be referred to as the dialysis membrane in order to avoid confusion with the phospholipid membranes.

The bigger barrel was filled with $15 \mathrm{ml}$ of the same solution that was used to eluate the REVs from the Sephadex column. A light cell was placed on top of this barrel. The system actually is assumed to be built up of 4 compartments. The REVs in the smaller barrel make 3 compartments: an internal aqueous phase (compartment 1), a membranous phospholipid phase (compartment $M$ ) and an external aqueous phase (donor compartment $D$ ). The solution in the larger barrel makes a second external aqueous phase (receptor compartment $\mathbf{R}$ ).

At the beginning of an efflux experiment compartments $I$ and $M$ contain warfarin, whereas compartments $D$ and $R$ do not. The assemb'y was turning around at $60 \mathrm{~Hz}$ on a roller mixer at $30^{\circ} \mathrm{C}$. Warfarin was measured at $308 \mathrm{~nm}$ in a thermostated cuvet-holder, at $30^{\circ} \mathrm{C}$ at fixed time intervals.

Measurement of the diffusion of warfarin through the Millipore filter in the absence of vesicles

The smaller barrel was filled with $2 \mathrm{ml}$ warfarin $(0.4 \mathrm{mM}) . \mathrm{NaOH}(10 \mathrm{mM})$ and $\mathrm{NaCl}(0 \mathrm{mM}, 30 \mathrm{mM}, 100 \mathrm{mM}, 600 \mathrm{mM}, 1000 \mathrm{mM})$. As before a Millipore filter was applied on top of this barrel. Then the larger barrel was filled with $15 \mathrm{ml}$ of the same solution except that warfarin was absent. A light cell was applied to the top of this barrel and the assembly was placed on the roller mixer under the same conditions as pointed out before. Warfarin again was measured at $308 \mathrm{~nm}$, at fixed time intervals.

\section{Results and Discussion}

Influence of $\mathrm{Na}^{+}$concentration on the partitioning of warfarin between phospholipid and aqueous phase

A linear relationship (Eqn. 9) between $\log K_{\text {upp }}$ and the negative logarithm of the sodium ion concentration represented as $\mathrm{pNa}$ was found over the whole $\mathrm{Na}^{+}$ concent! ation range investigated.

$\log \mathrm{K}_{\text {app }}=-0.30( \pm 0.02) \mathrm{pNa}+1.02( \pm 0.02)$

$(\mathrm{n}=5, r=0.995, \mathrm{~s}=0.03)$ 
This result was used to calculate the apparent partition coefficient of warfarin between the internal aqueous phase and the phospholipid membrane phase of the vesicles at the beginning of an efflux experiment.

The $\mathrm{pNa}$ values used in our experiments are all between 0.00 and 2.00. This implies that $\log \mathrm{K}_{\text {app }}$ varies between 0.4 and 1.0 according to Eqn. 9. This change is much smaller than was observed earlier by van der Giesen and Janssen (1982) using octanol as the organic phase. They found the coefficient of $\mathrm{pNa}$ to be -1.00 in comparable experiments in the $\mathrm{pNa}$ range of -0.4 to 1.2 . Later experiments covering a wider range, showed that this coefficient in fact was near -0.6 (van der Giesen, unpublished experiments). This different value of the coefficient of $\mathrm{pNa}$ demonstrates the effect of the organic phase on the partition behavior of sodium warfarin ion-pairs.

The effect of the character of the organic phase on partition coefficients is well documented and mostly described by a Coliander-type equation (Leo, 1972). From the results mentioned above a relationship between partition coefficients in DPPC and octanol can easily be derived for sodium warfarin ion-pairs. This relation will take the form:

$\log K_{\text {spp }}(D P P C)=a \log K_{a p p}($ octanol $)+b$

where $a$ and $b$ are constants. A value between 0.3 and 0.5 for a has to be expected. This means that the discriminative power of LPPC is much smaller than that of octanol. This is in accord with recently reported results (Arrowsmith et al., 1983) concerning the par:itioning of aliphatic cortisone-21 esters in DPPC liposomes. They reported that the incremental free energy of partitioning per methylene group was strongly dependent on chain length. Its value appears to be much lower than the value of $-3.0 \mathrm{~kJ}$ per $\mathrm{CH}_{2}$ (in octanol). calculated from the hydrophobic fragmental constant value of 0.53 (Rekker and de Kort. 1979) using the method described carlier (Janssen and Perrin, 1976).

Further it should be noted that the experiments in the present investigation were performed at $30^{\circ} \mathrm{C}$, i.e. about $11^{\circ} \mathrm{C}$ below the plase transition temperature of I)PPC. The partitioning of solutes between phospholipid bilayers and water has heen reported to depend on temperature and especially on the phase. either gel or licquid crystalline phase. of the bilityers (Ahmed et al, 1981; Melchior and Steim. 1976). Partition coefficients seen to he lower in the case of hilayers in the gel phase. Probably the more tight chain packing in bilayers in the gel phase is responsible for the reduction of partition coefficients urder those conditions (Cohen, 1975). A trat ght comparison with organic liquid and water systems is hampered becaluse pho:pholipid hilayers do noi constitute a homogeneous organic phase. The inner core somsists of long-chain phospholipid tail: that represent a more lipophilic region whercas the outer core consists of polar phospholipid head groups that represent a more bydrophilic: region.

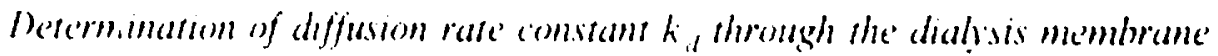

The diffusion of warlarin through the Millipore membrane used to separate the 
TABLE 1

INFLUENCE OF $\mathrm{Na}^{*}$ CONCENTRATION ON WARFARIN TRANSPORT

\begin{tabular}{cllc}
\hline $\mathrm{pNa}$ & $\mathrm{k}_{\mathrm{d}}\left(10^{-3} \mathrm{~min}^{-1}\right)$ & $\mathrm{k}_{\mathrm{r}}\left(10^{-3} \mathrm{~min}^{-1}\right)$ & $\mathbf{P}\left(10^{-6} \mathrm{~cm} \cdot \min { }^{-1}\right)$ \\
\hline 1.87 & 20.5 & 1.4 & 9.7 \\
1.23 & 20.8 & 1.7 & 9.8 \\
0.84 & 21.5 & 1.8 & 7.0 \\
0.10 & 20.9 & 4.6 & 13.1 \\
-0.11 & 20.0 & 4.0 & 11.1 \\
\hline
\end{tabular}

$\mathrm{pNa}=$ negative logarithm of $\mathrm{Na}^{+}$concentration; $\mathrm{k}_{\mathrm{d}}=$ Millipore filter diffusion iranspon contant of warlarin determined in absence of REVs according to Eqn. $11: k_{t}=$ release rate constant of warlann from REVs according to Eqn. 18 (mean standard deviation $=0.10 \times 10^{-3}$ ): $P=$ permeability constant 6 of the release of warfarin from REVs according to Eqn. 19.

vesicles from the receptor compartment will obey reversible kinetics. The diffusion rate was measured in the absence of vesicles. Eqn. 11 describes this process:

$\ln \left(1-\frac{C_{R .1}}{C_{D .0}} \cdot \frac{V_{R}+V_{D}}{V_{D}}\right)=-k_{d} t$

(Albery et al., 1976; Guy and Hadgraft, 1981) where $k_{d}$ is the diffusion transport constant, $C_{R . t}$ is the concentration of the diffusing warfarin in the receptor compartment $R$ at time $t, C_{D_{w}}$ is the concentration of warfarin in the donor compartment $D$ at time zero. $V_{R}$ and $V_{D}$ represent the volumes of the $R$ and $D$ compartment. In Eqn. 11 it is assumed that $C_{R .1}$ is zero at the start of an experiment. It should be noted that the diffusion transport constant $k_{d}$ is a function of $V_{R}$ and $V_{C}$ as itell

$\mathrm{k}_{\mathrm{d}}=\mathrm{k}_{\mathrm{d}}^{*}\left(\mathrm{~V}_{\mathrm{D}}^{-1}+\mathrm{V}_{\mathrm{R}}^{-1}\right)$

In our experiments $C_{R, t}$ is the quantity which is measured spectrophotometrically. When the results are analyzed according to Eqn. 11. the $k_{\mathrm{d}}$ values as reported in Table 1 are obtained. The average value is $0.0208 \mathrm{~min}^{-1}$. which corresponds with a $\mathrm{t}_{1 / 2}$ (defined as the time when the concentration in the receptor compartment has reached half of the final value) of $34 \mathrm{~min}$.

It is obvious that $\mathrm{k}_{\mathrm{u}}$ does not depend on $\mathrm{Na}^{+}$concentration. This indeed has to be expected because in this situation the diffusion through aqueous channels in the dialysis membrane will be rate-limiting. Hereafter the average value of $k_{\text {, }}$ will be used as a $\mathrm{Na}^{+}$concentration-independent constant.

\section{Influence of $\mathrm{Na}^{+}$concentration on elution pattern}

The isolation procedure described in the section Materials and Methods proved to be very reliable and effective. The total amount of warfarin eluted from the Sephadex column, i.e. the sum of the amount of warfarin encapsulated in the REVs (first peak) and the amount of iree warfarin (second peak) was always almost equal to the total amount of warfarin used for the preparation of the REVs. The first $2 \mathrm{ml}$ 


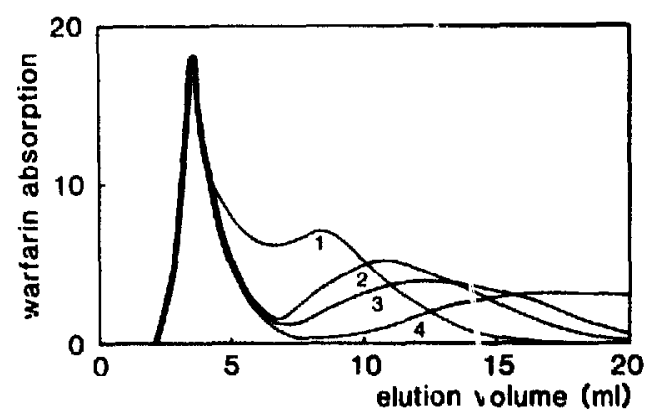

Fig. l. Isolation of warfarin containing REVs. Warfarin absorption at $308 \mathrm{~nm}$ of subsequent fractions of a REV preparation eluted from Sephadex columns. pNa of REV preparations: $1=1.87 ; 2=1.23: 3=084$ : $4=-0.11$.

of vesicles dropping from the column were not conta.ninated with bulk warfarin at any $\mathrm{Na}^{+}$concentration as can be seen from Fig. 1. When the vesicles were rechromatographed the bulk free warfarin peak had completely disappeared. The isolation procedure, therefore, is suited for the purpose of quick and effective separation. Table 2 gives a summary of the composition of the REV preparations used in the experiments. The internal volume of the REVs at the lowest $\mathrm{Na}^{+}$ concentration used amounts to $11.8 \mu \mathrm{l} / \mathrm{mg}$ phospholipid. Furthermore there appears to be a gradual decrease of the internal volume when the $\mathrm{Na}^{+}$concentration is raised. Both observations are in good agreement with the findings of Szoka and Papahadjopoulos (1978).

Release of warfarin from REVs and analysis of release experiments

The release of warfarin was followed by measuring the increase in absorbance in the receptor compartment over at least $5 \mathrm{~h}$. It appeared that about $25 \%$ of the total warfarin encapsulated in the REVs was released during this time.

The results were analyzed according to the model described by Chowhan et al. (1972). In this model it is assumed that the drug instantaneously partitions between phospholipid and internal aqueous phase and that the only barrier to transport from

TABI.1: 2

INCAPSULATION PARAMETERS OF VESICLE PREPARATIONS

\begin{tabular}{cccccc}
\hline$p N_{a}$ & $\mathrm{~K}_{\text {app }}$ & $\mathrm{m}_{1}(\mu \mathrm{mol})$ & $\mathrm{m}_{\mathrm{M}}(\mu \mathrm{mol})$ & $\mathrm{V}_{1}(\mu \mathrm{l})$ & $\mathrm{V}_{\mathrm{M}}(\mu \mathrm{l})$ \\
\hline 1.87 & 2.9 & 0.58 & 0.11 & 72 & 4.7 \\
1.23 & 4.5 & 0.60 & 0.21 & 72 & 5.6 \\
0.84 & 5.9 & 0.32 & 0.23 & 46 & 5.6 \\
0.10 & 0.8 & 0.17 & 0.28 & 25 & 4.3 \\
0.11 & 11.2 & 0.20 & 0.39 & 30 & 5.3 \\
\hline
\end{tabular}

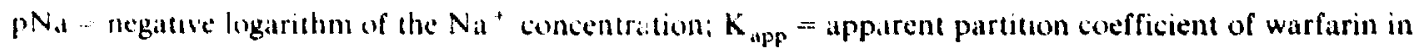
the system $D P P C$-water. Note that $K_{\text {app }}$ values in this table are calculated from Eqn. $9: m_{1}=$ amount of warfarin inside the REVs at $1=0 ; m_{M}=$ anount of warfarin in phospholipid membrane at $1=0 . V_{1}$. $v_{\mathrm{N}}=$ internal and membrane volume of REV's. For further details see text. 
the vesicles is located at the external lipid-aqueous interface. The release of warfarin from our REVs then, according to the model. may be described by Eqn. 13:

$$
-\frac{d C_{A}}{d t}=k_{r}\left(C_{1}-C_{D}\right)
$$

where $C_{A}$ is the average concentration of warfarin on the inside of the barrier, $C_{1}$ is the concentration in the internal aqueous phase of the vesicles, $C_{D}$ is the concentration in the donor compartment $D$ and $k$, is a velocity constant. It can be calculated that during the course of an efflux experiment $C_{D} \ll C_{1}$. With this assumption Eqn. 13 may be written as:

$$
-\frac{d C_{A}}{d t}=k_{r} C_{1}
$$

Chowhan et al. obtained irreversibie transport kinetics from the donor compartment to the receptor compartment by keeping the concentration in the receptor compartment zero (sink conditions). However, in our experimental approach. we had to take into consideration the back transport from the receptor compartment $R$ to the donor compartment $D$. The rate expression for warfarin concentration in compartment $D$ then will be given by:

$$
\frac{d C_{D}}{d t}=-\frac{V_{1}+V_{M}}{V_{D}} \cdot \frac{d C_{A}}{d t}-\frac{V_{R}}{V_{D}+V_{R}} \cdot k_{d} \cdot\left(C_{D}-C_{R}\right)
$$

The rate expression for warfarin concentration in compartment $\mathbf{R}$ finally is given by:

$$
\frac{d C_{R}}{d t}=\frac{V_{D}}{V_{D}+V_{R}} \cdot k_{d} \cdot\left(C_{D}-C_{R}\right)
$$

The solution of Eqns. 14-16 results in:

$$
C_{R, 1}=\frac{m_{1}+m_{M}}{V_{D}+V_{R}} \cdot\left[1-\frac{1}{k_{d}-k_{r}^{*}}\left(k_{d} e^{-k_{i}^{*} t}-k_{r}^{*} e^{-k_{d} t}\right)\right]
$$

where

$$
k_{r}^{*}=\frac{V_{1}+V_{M}}{V_{1}+K_{u p p} V_{M}} \cdot k_{r}
$$

In Eqn. 17. where the warfarin concentration in the receptor compartment $C_{R . t}$ is expressed as a function of time, all constants are known except for the velocity constant $k_{r}^{*}$. By substituting our efflux data into this equation we could derive the best fitting values for $\mathrm{k}_{r}^{*}$ and $\mathrm{k}_{\mathrm{r}}$ at different $\mathrm{Na}^{+}$concentrations by means of a non-linear least-squares program. These values are shown in Table 1 . The release 
rate of warfarin expressed in terms of the velocity constant $k_{r}$ has increased by about a factor 2.5 at the higher $\mathrm{Na}^{+}$concentrations. However, the physical meaning of this increase is restricted because $k_{r}$ will depend on total internal volume and total membrane surface. As the internal volume $\left(V_{1}\right)$ is decreasing at higher $\mathrm{Na}^{+}$ concentration (see Table 2) and as total membrare surfaces will depend on the total amount of lipid present, the values of $k_{r}$ should te corrected to get true permeabilities. Therefore the results finally were expressed in terms of permeability coefficients P:

$P=\frac{k_{r} V_{1}}{S_{M}}$

where $S_{M}$ represents the total membrane surface of vesicles in a specific experiment. $S_{M}$ was calculated as the quotient of total membrane volume $\left(V_{M}\right)$ and membrane thickness (42 A). The permeability coefficients $\mathrm{P}$ at different $\mathrm{Na}^{+}$concentrations are shown in Table 1. It now appears that all perme:tbilities are of the same order of magnitude and, notwithstanding the numerous ex jerimental manipulations, almost equal. Therefore it may be inferred from this fina result that if there should be an influence of $\mathrm{Na}^{+}$concentration on permeability then it certainly is a very small effect.

\section{Concluding Remarks}

Recently Arrowsmith et al. (1983) investigated the release of aliphatic cortisone-21 esters from DPPC liposomes. From their experiments these authors concluded that the less hydrophobic steroids are leaking faster frem liposomes. This phenomenon, which is opposite to what might be expected. was explained by the assumption of steroid retention in the phospholipid bilayers. Because Arrowsmith et al. studied the efflux of highly hydrophobic compounds from mu tilamellar liposomes, which have a comparatively small internal water-phospholipid ratio, only a very small fraction of the diffusing solute will be present in the interral aqueous compartments of the liposomes. It should be realized that under such conditions mainly the efflux from the phospholipid membranes is studied. This same cemark holds for the experiments of Ahmed et al. (1980) concerning the efflux of pienothiazines from multilamellar liposomes. In car experimerts the objective was to investigate drug transport from the inside of vesicles across the phospholipid membranes to the outside. For this purpose we used REVs which have a relatively hign water-phospholipid ratio.

From our results we have to conclude that warfarin permeability of REVs under the documented conditions does not clearly depend on $\mathrm{Na}^{+}$concentration, whereas warfarin partitioning between phospholipid membrane phase and aqueous phase does depend indisputably on $\mathrm{Na}^{+}$concentration. This is in contrast with the results of our previous study (Cools and Janssen, 1983) where we investigated the same subject using octanol-impregnated filters instead of the more complicated vesicle membrane system in the present study. The difference in outcome may be explained 
in several ways. Of all possibilities we wish to mention a few. For example. it cannot be excluded that the diffusion from the internal aqueous phase of a vesicle to the phospholipid membrane is the rate-limiting step due to the formation of an unstirred diffusion layer as a consequence of insufficient mixing on that side of the vesicle membrane. Another possibility is that the increase in ionic strength at higher $K_{\text {app }}$ values introduces an artefactual effect on permeability characteristics. Also it is possible that the actual variation of $\mathrm{K}_{\text {app }}$ values is too small to allow a detectable influence on the permeability in the vesicle membrane approach. To obtain more insight in the validity of the documented method it now seems appropriate to test a series of compounds covering a compichensive range of lipophilicity without the inevitability of simultaneous changes in ionic strength.

\section{References}

Ahmed, M., Burton, J.S., Hadgraft, J. and Kellaway. I.W., Paritioning and efflux of phenothazmes itom liposumes. Biochem. Pharmacol., 29 (1980) $2361-2365$.

Ahmed, M., Burton, J.S., Hadgraft. J. and Kellaway, I.W.. Thermodynamics of partitioning and eifux of phenıthiazines from liposomes. J. Membr. Biol., 58 (1981) $181-189$.

Albery, W.J., Burke. J.F.. Leffler, E.B. and Hadgraft. J., Interfacial transfer studies with a rotating diffusion cell. J. Chem. Soc. Faraday Trans. I, 72 (1976) 1618-1626.

Arrowsmith, M., Hadgraft, J. and Kellaway, I.W.. The in vitro release of steroids from liposomes. Int. $J$ Pharn.. 14 (1983) 209-221.

Bangham, A.D. Standish, M.M. and Watkins, J.C., Diffusion of univalent ions across the lamellac of swollen phospholipids. J. Mol. Biol., 13 (1965) $238-252$.

Chapmar, D., Williams, R.M. and Ladbrooke, B.D. Thermotropic and lyotropic mesomomhism of some 1,2-diacyl-phosphatidyl cholines (lecithins). Chem. Phys. Lipids, 1 1967, 445-475

Chowhan, Z.T., Yotsuyanagi, T. and Higuchi, W.I., Model transport studies utilizing lecithin spherules Bioch m. Biophys. Acta. 266 (1972) 320-342.

Cohen, B E., The permeability of liposomes to nonelectrolytes. J. Membr. Biot., 20 (1975) 205234

Cools, A.A. and Janssen. L.H.M., Influence of sodium ion-pair formation on transport kinctics af warfarin through octanol-impregnated membranes. J. Pharm. Pharmacol. 35 (1983) 689-691

Guy, R.H. and Hadgraft. J., Interfacial transport of salicylic atid. J. Collond Interface Sut. 81 (1981) $69-74$.

Hermettel, A. and Paltauf, F.. Permeability properties of untamellar vesicles contat ning tholine plasmalogens and comparison with other choline glycerophospholipid species. Chem. Phy. Lipits. 29 (1981) $225-233$.

Jaussen, I..H.M. and Perrin. J.H., Some theoretical observations on the estimation of partition coefficients from $r$ and $f$ constants. Eur. J. Med. ( hem., 11 (1976) 197-200).

Juliano, Fi.L. and Stamp. D., Interaction of drugs with lipid membrancs. Bionhim. Biophy. Acta. Sk6 (1979) $137-145$.

L.eo. A.J.. Relationships hetween partitoming v vent systems. In Ciould, R.F. (Ed.). Biologetcal correla tions--. the Hansch approach, Advales ... Chemistry Series 114. Americtn Chemical Soxiely Washingtun, 1972, pp. $51-60$.

Levine, Y.K., Lee, A.G., Birdsall, N.J.M., Metcalfe, J.C. and Robinson. J.D. The interaction al paramagnetic ions and spin labels with lecithin bilayers. Biochim. Biophys. Acta. $291(1973) 592607$

Melchior, D.R. and Steim. J.M.. Thermotropic transitions in hiomembrancs. Ann Res. Buphys. Bueng. 5 (1976) 205238 .

Muranushi, N., Nakajima. Y., Kinugawa, M.. Muranishi, A. and Sezaki. H. Mechanism for the inducement of the intestinal absorption of poorly absorhed drugs by mixed micelles. It. Effect of the incorforation of various lipids on the permeability of liposomal membranes. Int. J. Pharm.. $4(19 \mathrm{k0})$ $281-290$. 
Rekker, R.F. and De Kort, H.M., The hydrophobic fragme utal constant; an extension to a 1000 data point set. Eur. J. Med. Chem., 14 (1979) 479-488.

Szoka, F. and Papahadjopoulous, D., Procedure for preparation of liposomes with large internal aqueous space and high capture by reverse-phase evaporation. Proc. Natl. Acad. Sci. U.S.A., 75 (1978) 4194-4198.

Van Der Giesen, W.F, and Janssen, L.H.M., Influence of ionization and ion-pair formation on lipophilicity of some 4-hydroxycoumarin derivatives in the systern octanol-water. Int. I. Pharm., 12 (1982) 231-249. 